\title{
Model-Based Assessment of Climate Change Impact on Isaac River Catchment, Queensland
}

\author{
Nahlah Abbas ${ }^{1}$, Saleh A. Wasimi' ${ }^{1}$, Nadhir Al-Ansari ${ }^{2}$ \\ ${ }^{1}$ School of Engineering \& Technology, Central Queensland University, Melbourne, Australia \\ ${ }^{2}$ Department of Civil, Environmental and Natural Resources Engineering, Lulea University of Technology, \\ Lulea, Sweden \\ Email: n.abbas@cqu.edu.au, s.wasimi@cqu.edu.au, nadhir.alansari@ltu.se
}

Received 7 June 2016; accepted 23 July 2016; published 26 July 2016

Copyright (C) 2016 by authors and Scientific Research Publishing Inc.

This work is licensed under the Creative Commons Attribution International License (CC BY). http://creativecommons.org/licenses/by/4.0/

(c) (i) Open Access

\begin{abstract}
Isaac River catchment, which is located within Fitzroy basin in Central Queensland, Australia is mostly a semi-arid region, sparsely populated, but rife with economic activities such as mining, grazing, cropping and production forestry. Hydro-meteorological data over the past several decades reveal that the catchment is experiencing increasing variability in precipitation and streamflow contributing to more severe droughts and floods supposedly due to climate change. The exposure of the economic activities in the catchment to the vagaries of nature and the possible impacts of climate change on the stream flow regime are to be analyzed. For the purpose, SWAT model was adopted to capture the dynamics of the catchment. During calibration of the model 12 parameters were found to be significant which yielded a R2 value of 0.73 for calibration and 0.66 for validation. In the next stage, six GCMs from CMIP3 namely, CGCM3.1/T47, CNRM-CM3, GFDLCM2.1, IPSLCM4, MIROC3.2 (medres) and MRI CGCM2.3.2 were selected for climate change projections in the Fitzroy basin under a very high emissions scenario (A2), a medium emissions scenario (A1B) and a low emissions scenario (B1) for two future periods (2046-2064) and (2080-2100). All GCMs showed consistent increases in temperature, and as expected, highest rate for A2 and lowest rate for B1. Precipitation predictions were mixed-reductions in A2 and increases in A1B and B1, and more variations in distant future compared to near future. When the projected temperatures and precipitation were inputted into the SWAT model, and the model outputs were compared with the baseline period (1980-2010), the picture that emerged depicted worsening water resources variability.
\end{abstract}

\section{Keywords}

Climate Change, Isaac River, SWAT Model, Water Resources 


\section{Introduction}

Australia is known as the driest continent of the world, and with its stressed water resources, there is veritable evidence that climate change would stress it even further [1]. Evidence is now growing that climate change would enhance extreme weather events such as tropical cyclones, floods, droughts and bushfires which would impact on water resources of a region [2]. Isaac River catchment in central Queensland is exposed to all these vagaries of nature.

The ex-Prime Minister of Australia, Kevin Rudd, once called climate change "the greatest moral, economic and social challenge of our time”. His words reflect the vulnerability of Australia to climate change. It can adversely affect water resources with flow on effect on the environment and economy. Decision makers are now seeking answers as to how they should plan for the future to counter the adverse effects of climate change.

But, unfortunately so far, water issues related to climate change have not been well addressed within climate change analyses and climate policy construction [3]. This fact has been underscored in Australian government papers [4]. This study aims to fill that gap by investigating the impact on water resources of the Isaac River catchment using the mathematical tool SWAT, which has been already applied elsewhere in the world with satisfactory results.

\section{Study Area}

Isaac River is one of the major tributaries and the main hydrological driver of the Fitzroy River Basin, contributing about 50\% of the Fitzroy's flow [5]. It is located in the north of the Fitzroy Basin approximately between 21.270S latitude and 148.110E longitude and is close to the coast along its eastern edge (Figure 1). The Isaac River drains an area of 22,446 $\mathrm{km}^{2}$ and discharges into the Mackenzie River. The mean annual discharge is $1,960,000 \mathrm{ML}$ and the total length of the channel is $457 \mathrm{~km}$.

The climate of the Fitzroy Basin is tropical to sub-tropical, ranging from semi-arid inland to humid near the coast, with wet summers and mild to dry winters. The mean annual temperature varies from $19.2^{\circ} \mathrm{C}$ in the south to $22.6^{\circ} \mathrm{C}$ in the north. There is a high level of rainfall variability within the catchment due to climatic drivers such as ENSO and the Pacific Decadal Oscillation (PDO) [6]. Mean annual rainfall ranges from higher rainfall areas close to the coast with up to $1800 \mathrm{~mm}$ in the east to $600 \mathrm{~mm}$ in the west. Flow regime is highly variable within and between years, and greater than $90 \%$ of flow occurs in the wet season from December to May.

The soils of the Isaac Basin are very diverse owing to large variations in lithology, climate and geomorphic processes. There are recorded more than 100 soil types present in the catchment and no one soil group is dominant [7]. At various locations within the Isaac catchment, there are coal mining activities. The most common land uses in the catchment are cattle grazing, irrigated and dry-land cropping and production forestry [8].

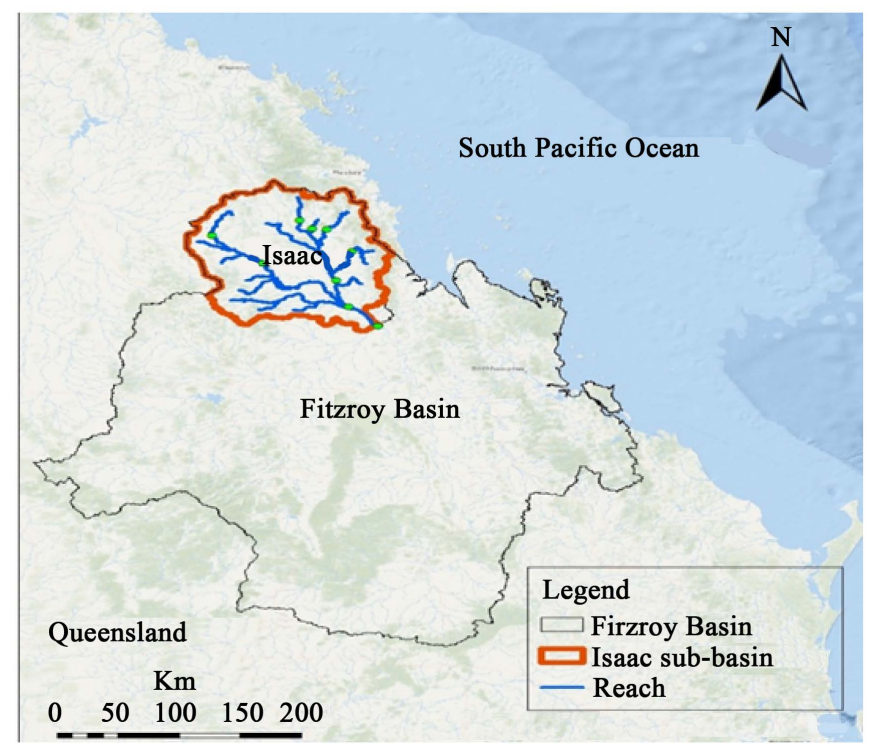

Figure 1. Location of Isaac River catchment. 


\section{Description of SWAT Model}

The Soil and Water Assessment Tool (SWAT) model [9], used in this study, is a river watershed scale, semi-distributed and physics-based discrete time (daily computational time step) model for analyzing hydrology and water quality at various watershed scales with varied soils, land use and management conditions on a longterm basis. The model was originally developed by the United States Department of Agriculture (USDA) and the Agricultural Research Service (ARS). SWAT system is embedded within a Geographic Information System (ArcGIS interface) in which different spatial environmental data, including climate, soil, land cover and topographic characteristics can be integrated.

Two major modules, land phase and routing phase, are run to simulate the hydrology of a watershed. The land phase of the hydrological cycle predicts the hydrological components including surface runoff, evapotranspiration, groundwater, lateral flow, and return flow. The routing phase of the hydrological cycle is the movement of water, sediments, nutrients and organic chemicals via the channel network of the basin to the outlet. The estimation of surface runoff is done through two methods; the SCS curve number procedure (SCS 1972 [9]) and the Green and Ampt infiltration method [10].

The SCS method has been used in this study due to non-availability of sub-daily data that is required by the Green and Ampt infiltration method. The model estimates the volume of lateral flow depending on the variation in conductivity, slope and soil water content. A kinematic storage model is utilized to predict lateral flow through each soil layer. Lateral flow occurs below the surface when the water rates in a layer exceed the field capacity after percolation.

The groundwater simulation is divided into two aquifers which are a shallow aquifer (unconfined) and a deep aquifer (confined) in each watershed. The shallow aquifer contributes to streamflow in the main channel of the watershed. Water that percolates into the confined aquifer is presumably contributing to streamflow outside the watershed. Three methods are provided by SWAT model to estimate potential evapotranspiration (PET) — the Penman-Monteith method, the Priestley-Taylor method and the Hargreaves method. Water is routed through the channel network by applying either the variable storage routing or Muskingum river routing methods using the daily time step.

A. Model Input

Enormous amount of input data is required by SWAT model to fulfill the tasks envisaged in this research. Basic data requirements for modeling included digital elevation model (DEM), land use map, soil map, weather data and discharge data. Data were compiled from different sources. DEM data was obtained from Queensland Department of Natural Resources and Mines with a 25 meter grid and $1 \mathrm{~km}$ spatial resolution

(https://data.qld.gov.au/). The land cover map was obtained from Queensland Government

(https://data.qld.gov.au/) with a 50m grid raster for the period of 1999 to 2009. The soil map was collected from the global soil map of the Food and Agriculture Organization of the United Nations [11]. Weather data included daily precipitation, 0.5 hourly precipitation, maximum and minimum temperatures, and were obtained from the Australian government's Bureau of Meteorology website (http://www.bom.gov.au/climate/data/). Daily streamflow and water quality data were collected from Queensland Department of Natural Resources and Mines/Water Monitoring Portal

(https://www.dnrm.qld.gov.au/water/water-monitoring-and-data/portal).

B. Model Setup

In SWAT model, the watershed is divided into sub-basins based on the digital elevation model (DEM). The land use map, soil map and slope datasets were embedded within the SWAT databases. Thereafter, sub-basins are further subdivided by Hydrologic Response Units (HRUs). HRUs are defined as packages of land that have a unique slope, soil and land use area within the borders of the sub-basin. HRUs enable the user to identify the differences in hydrologic conditions such as evapotranspiration for varied soils and land uses. Routing of water and pollutants are predicted from the HRUs to the sub-basin level and then through the river system to the watershed outlet.

C. Model Calibration and Evaluation

To evaluate the performance of the SWAT model, the sequential uncertainty fitting algorithm application (SUFI-2) embedded in the SWAT-CUP package [12] was used. The advantages of SUFI-2 are that it combines optimization and uncertainty analysis, can handle a large number of parameters through Latin hypercube sampling and it is easy to apply. Furthermore, as compared with different techniques in connection to SWAT such 
as generalized likelihood uncertainty (GLU) estimation, parameter solution (parsol), Markov Chain Monte Carlo (MCMC), SUFI-2 algorithm was found to obtain good prediction uncertainty ranges with a few number of runs. This efficiency is of great significance when implementing complex and large-scale models.

The SUFI-2 first identifies the range for each parameter. After that, Latin Hypercube method is used to generate multiple combinations among the calibration parameters. Finally, the model runs with each combination and the obtained results are compared with observed data until the optimum objective function is achieved. Since the uncertainty in forcing inputs (e.g. temperature, rainfall), conceptual model and measured data are unavoidable in hydrological models, the SUFI-2 algorithm computes the uncertainty of the measurements, the conceptual model and the parameters by two measures: P-factor and R-factor. P-factor is the percentage of data covered by the 95\% prediction uncertainty (PPU) and the R-factor is the average width of the 95 PPU divided by the standard deviation. Further, SUFI-2 calculates the Coefficient of Determination (R2) and the Nasch-Sutcliff efficiency (ENC) [13] to assess the goodness of fit between the measured and simulated data.

SUFI-2 enables users to conduct global sensitivity analysis, which is computed based on the Latin Hypercube and multiple regression analysis. The multiple regression equation is defined as below.

$$
g=\alpha+\sum_{i=1}^{m} \beta_{i} * b_{i}
$$

where $g$ is the value of evaluation index for the model simulations, $\alpha$ is a constant in multiple linear regression equation, $\beta$ is a coefficient of the regression equation, $b$ is a parameter generated by the Latin hypercube method and $\mathrm{m}$ is the number of parameters. Both $t$ and $p$ values in statistical methods are used to indicate parameter sensitivity.

\section{General Circulation Model (GCM) Inputs}

Six GCMs from CMIP3 namely CGCM3.1/T47, CNRM-CM3, GFDL-CM2.1, IPSLCM4, MIROC3.2 (medres) and MRI CGCM2.3.2 were selected for climate change projections in the Isaac river basin under a very high emission scenario (A2), a medium emission scenario (A1B) and a low emission scenario (B1) for two future periods (2046-2064) and (2080-2100). The projected temperatures and precipitation were then input to the SWAT model, which has already been calibrated for the Isaac River catchment, to compare water resources in the basin with the baseline period (1980-2010). BCSD method was used to downscale the GCM results [14]. The baseline period values are captured in Figure 2 and, it can be seen in the figure that there is considerable spatial variation in precipitation and water resources in the basin.

\section{Results and Discussion}

SWAT model appeared to capture the basin characteristics very well. The simulation runs produced results which were within acceptable level of tolerances from the observed values. The procedures adopted in this study to validate the suitability of the model are similar to the ones in published literature as has been done by other researchers elsewhere in the world with the same model. Comparisons have been made with the findings of other researchers for other basins where it has been deemed necessary and relevant.

A. Sensitivity analysis

SWAT has 25 parameters related to streamflow. During model calibration, it is essential that sensitivity analysis of these parameters be carried out and ranked. The non-influential parameters should be discarded from the model. With the observed data, 12 most sensitive parameters have been identified and ranked as given in Table 1.

The most sensitive SWAT calibration parameter was CN2 for the Isaac basin. In most SWAT applications in different watersheds it was found that CN2 was the dominant SWAT parameter [15]. ALPHA-BF was ranked as the second. This result is similar to the findings of Li et al. [16] who found that ALPHA is highly sensitive groundwater parameter in SWAT calibration.

B. Calibration and validation

The model was calibrated on a monthly scale for twenty two years (1979-2000) and validated for ten years (2001-2010) and the first three years was used as a warm up at the Yatton station which is located at the outlet of Isaac basin. Measured and simulated monthly flow at the Yatton discharge station in the Isaac Basin matched 


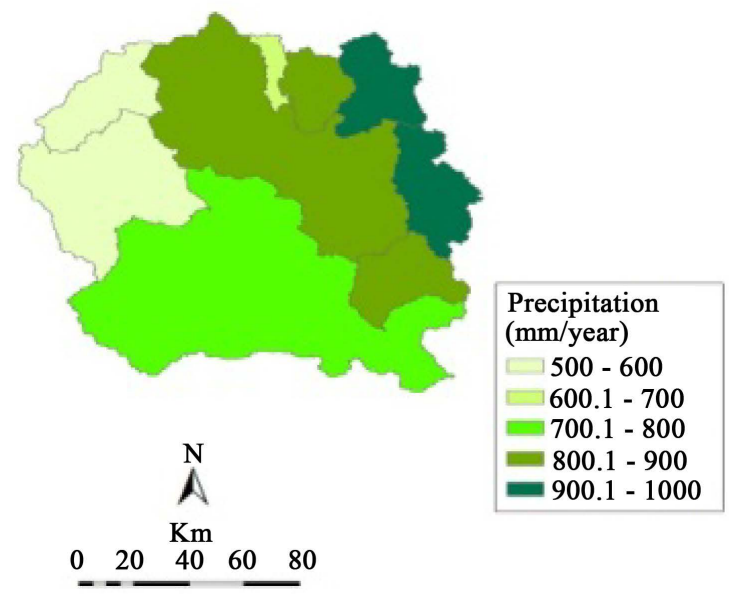

(a)

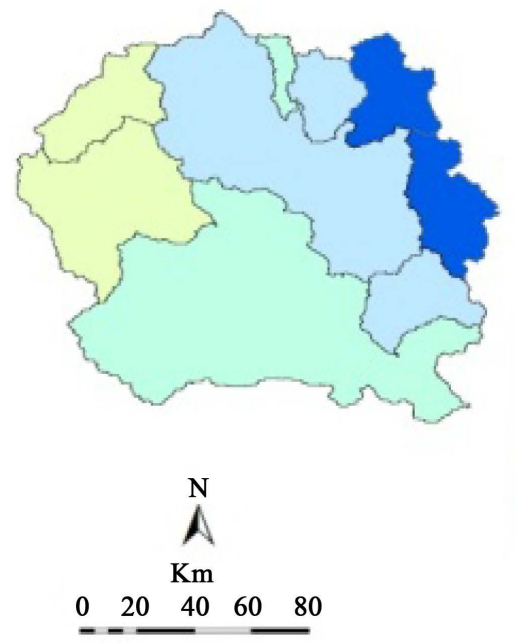

(c)

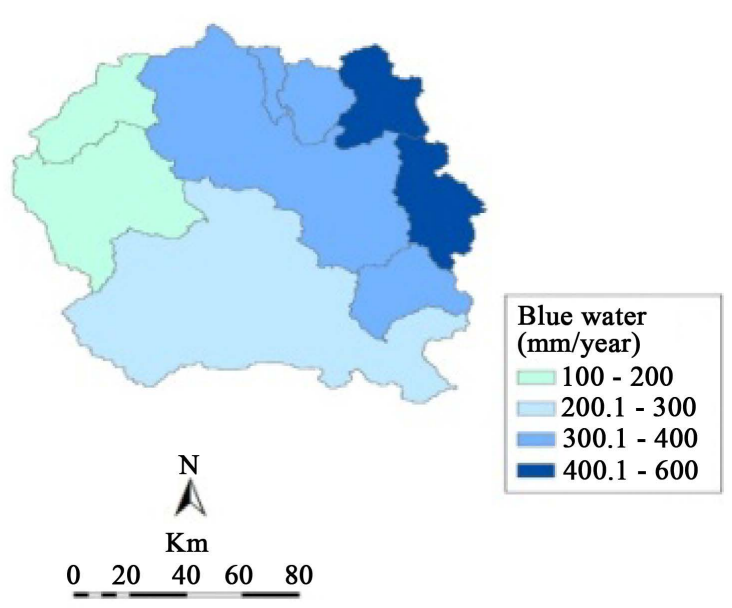

(b)

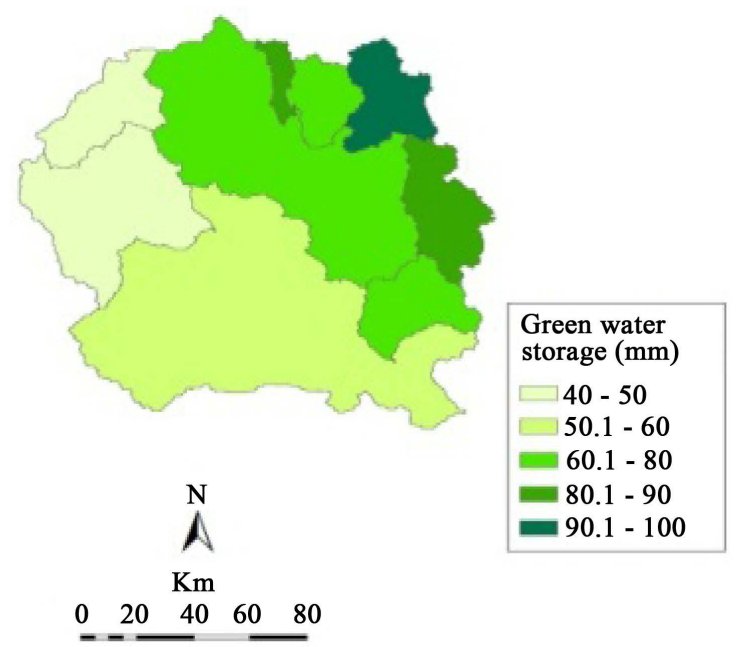

(d)

Figure 2. The (1980-2010) annual average (a) precipitation; (b) blue water; (c) deep aquifer recharge; (d) average green water storage in Isaac Basin.

Table 1. Most sensitive parameters (ranked) related to streamflow in the Isaac basin.

\begin{tabular}{cccc}
\hline Parameter & Rank & Initial values & Fitted values \\
CN2 & 1 & $-0.2-0.2$ & -0.12 \\
ALPHA_BF & 2 & $0-1$ & 0.95 \\
GW_DELAY & 3 & $30-450$ & 401 \\
CH_K2 & 4 & $5-130$ & 27.9 \\
OV-N & 5 & $-0.2-0$ & -0.19 \\
HRU_SLP & 6 & $0-0.2$ & 0.01 \\
ESCO.hru & 7 & $0.8-1$ & 0.85 \\
REVAPMN & 8 & $0-10$ & 2.5 \\
GW_REVAP & 9 & $0-0.2$ & 0.023 \\
SLSUBBSN & 10 & $0-0.2$ & 0.13 \\
SOL_AWC & 11 & $-0.2-0.4$ & -0.03 \\
GWQMN & 12 & $0-2$ & 1.83 \\
\hline
\end{tabular}


well in both calibration and validation processes as shown in Figure 3. During the calibration process, Both R2 and ENC were 0.73 . P-factor covered 0.42 of measured data and R-factor was 0.41 . During the validation, however, R2 and ENC decreased to 0.66 and 0.62 , respectively. P-factor decreased to 0.35 and R-factor increased to 0.51 .

C. Climate change scenarios: The impacts of climate change on air temperature and precipitation

Prior to identifying the impacts of climate change on water resources in the Isaac basin, mean annual temperature and precipitation outputs from the six GCMs were processed for three scenarios (A2, A1B, B1). Figure 4 captures the projected changes in mean annual temperature for two future periods (2046-2064) and (2080-2100)

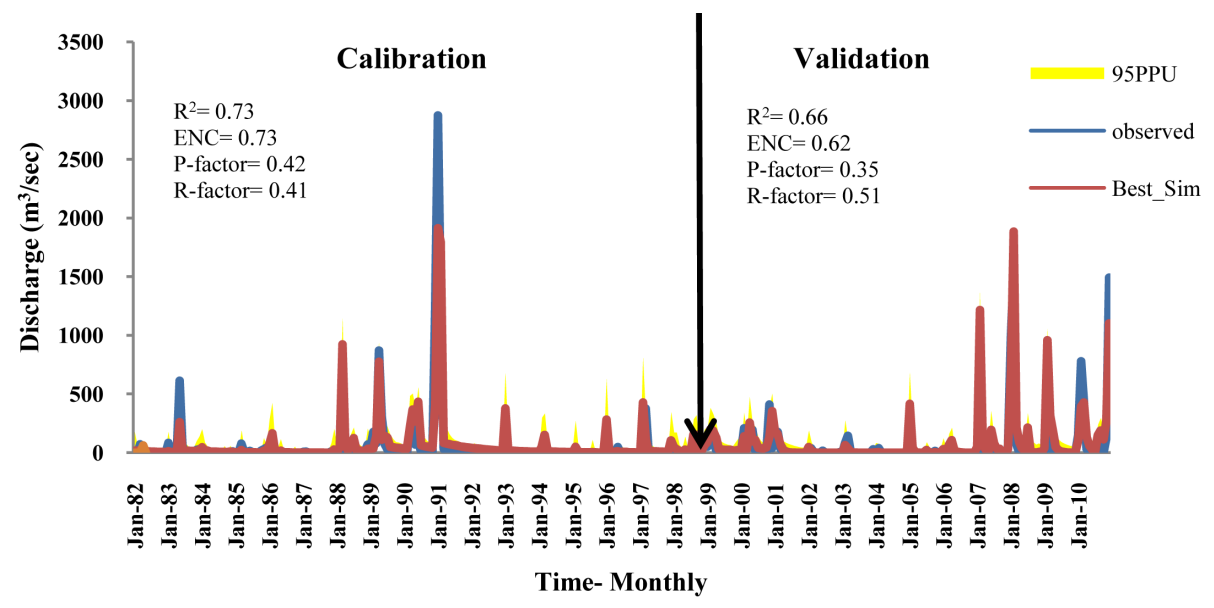

Figure 3. Calibration and validation of the SWAT model on monthly scale at Yatton Station. The solid vertical black line in the middle separates the calibration period from the validation period.

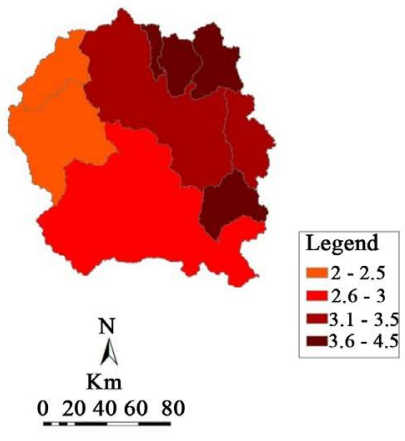

(a)

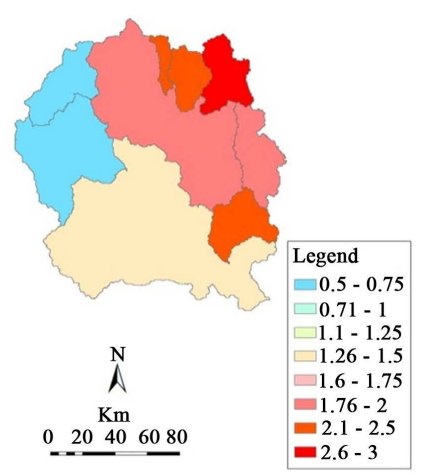

(d)

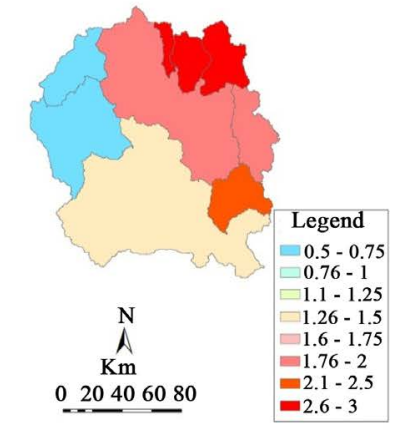

(b)

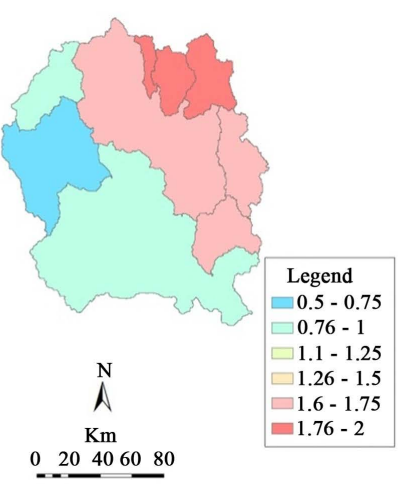

(e)

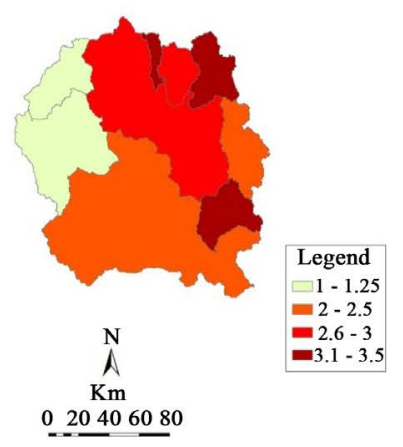

(c)

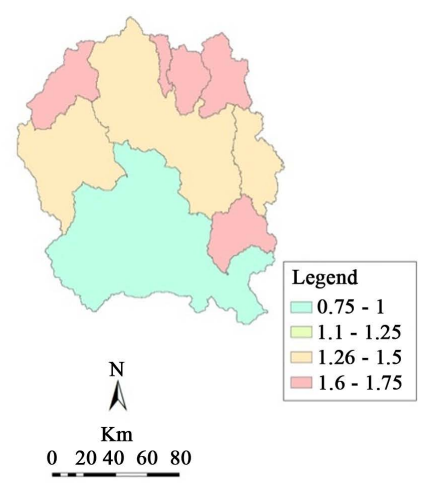

(f)

Figure 4. The impacts of climate change on mean annual temperature of the basin in ${ }^{\circ} \mathrm{C}$ (a) temperature anomaly based on scenario A2 for the period of 2080-2100; (b) anomaly for A2 for 2046-2064; (c) anomaly for A1B for 2080-2100; (d) anomaly for A1B for2046-2064; (e) anomaly for B1 for 2080-2100; and (f) anomaly for B1 for 2046-2064. 
relative to base period (1980-2010). Changes in mean temperature tend to be more stable than precipitation. All the models showed consistent increasing trends in temperature over Isaac basin under the three scenarios (A2, A1B, B1). As expected, A2 scenario projected the highest increases up to 20C and 3.50C for the period of 2046 to 2064 and 2080 to 2100, respectively. While B1 scenario showed the lowest increases which is expected to be up to $1.340 \mathrm{C}$ and $1.420 \mathrm{C}$ for the near future and the distant future, respectively. These results are consistent with results of [17] who found that, in Australia by 2070, projected average annual temperature may rise by $2.2^{\circ} \mathrm{C}$ to $5.0^{\circ} \mathrm{C}$ for high emissions and $1.0^{\circ} \mathrm{C}$ to $2.5^{\circ} \mathrm{C}$ for low greenhouse gas emissions.

Figure 5 shows the anomaly maps of precipitation distribution (maps of percent deviation from historic data, 1980-2010) for A2, A1B and B1 scenarios for the periods 2046-2064 and 2080-2100 for the average change of multi-GCM ensemble. All scenarios show an increase in precipitation trend for the near and distant future except under A2 scenario for the period (2046-2064). For near future, B1 scenario projected the highest increase (30\%) followed by A1B (8\%) while A2 showed reduction in precipitation over the basin which could be up to $5 \%$. In the distant future, the basin would experience more precipitation than near future under all three scenarios. The precipitation would increase up to $41 \%$ under B1 scenario followed by A1B (6\%) and then A2 (4\%). These outcomes confirm the results of earlier study [18] that this region will likely experience more rain due to longer and more intense monsoon resulting from more intense atmospheric convection.

D. Climate change scenarios: The impacts of climate change on blue and green waters

Figure 6 captures the anomaly maps of blue water distribution (maps of percent deviation from historic data, 1980-2010) for A2, A1B and B1 scenarios for the periods 2046-2064 and 2080-2100 for the average change of multi-GCM ensemble. The near half-century projection (2046-2064) showed an increase in blue water under all
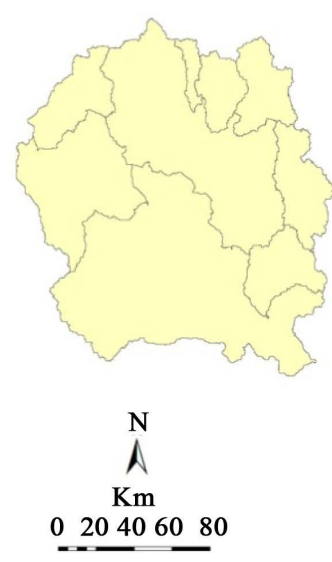

(a)

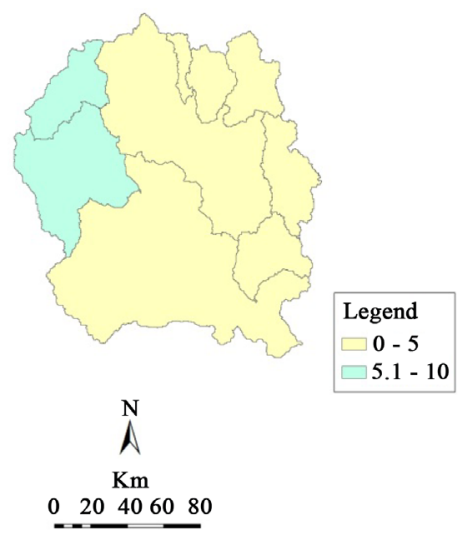

(d)

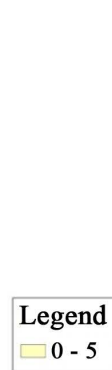

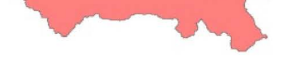
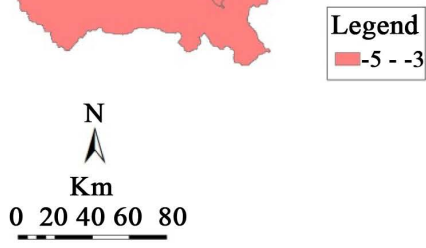

(b)

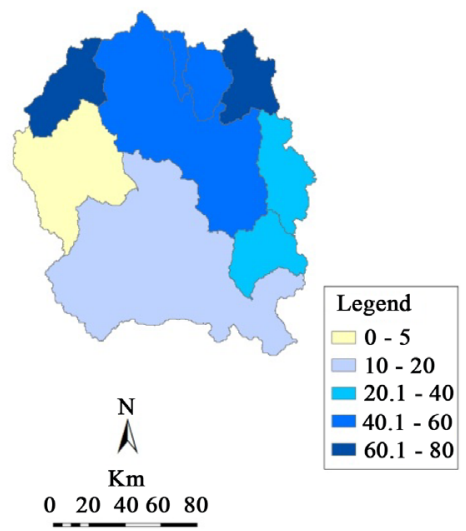

(e)
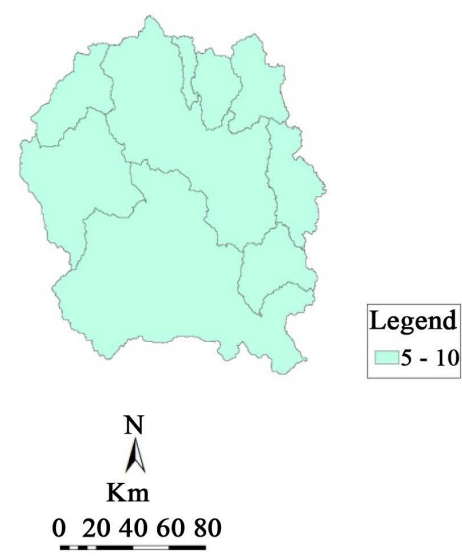

(c)

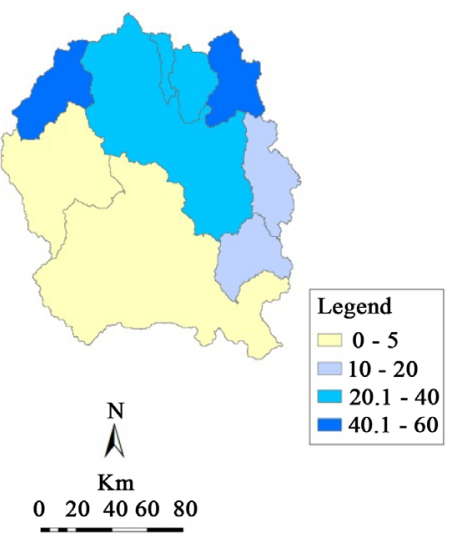

(f)

Figure 5. The impacts of climate change on precipitation of the basin in ${ }^{\circ} \mathrm{C}$ (a) precipitation anomaly based on scenario A2 for the period of 2080-2100; (b) anomaly for A2 for 2046-2064; (c) anomaly for A1B for 2080-2100; (d) anomaly for A1B for 2046-2064; (e) anomaly for B1 for 2080-2100; and (f) anomaly for B1 for 2046-2064. 

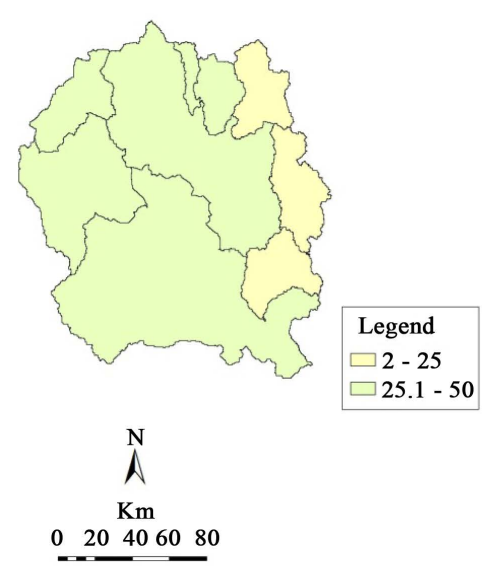

(a)

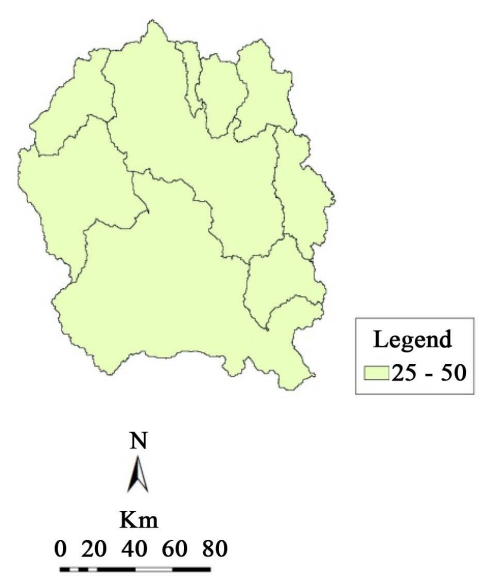

(d)
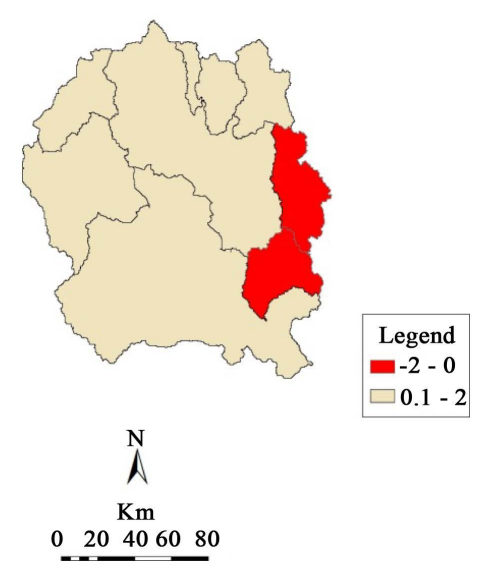

(b)

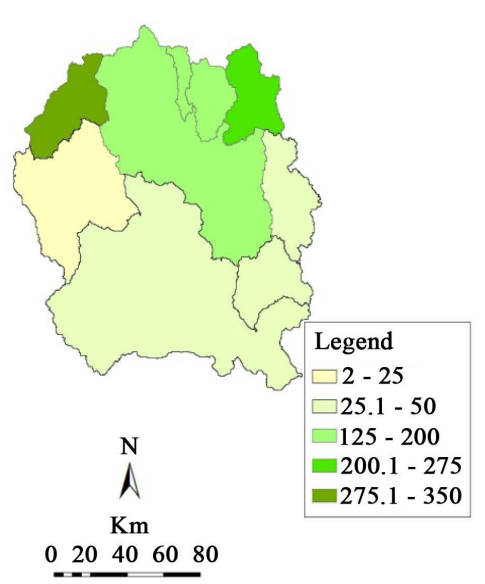

(e)
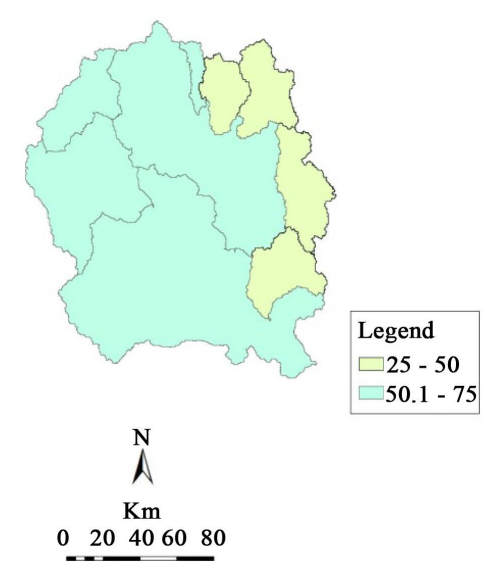

(c)

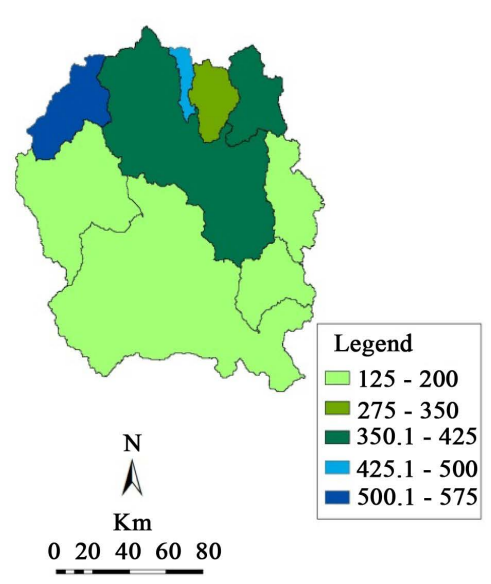

(f)

Figure 6. The impacts of climate change on the blue water resources of the basin in ${ }^{\circ} \mathrm{C}$ (a) anomaly based on scenario $\mathrm{A} 2$ for the period of 2080-2100; (b) anomaly for A2 for 2046-2064; (c) anomaly for A1B for 2080-2100; (d) anomaly for A1B for 2046-2064; (e) anomaly for B1 for 2080-2100; and (f) anomaly for B1 for 2046-2064.

emission scenarios for the whole basin. B1 scenario projected the highest increase (130\%) followed by A1B (47\%) and then A2 (5\%). In the near one-century future, the trends of blue water will increase to $300 \%, 50 \%$ and 29\% under B1, A1B and A2 emission scenarios, respectively. Similarly, green water storage will increase under the three emission scenarios for the two future periods except under A2 scenario for the period of (20462064) where green water decreased up to $10 \%$, which is captured in Figure 7. Generally, green water follows blue water, where blue water flows are high, green water flows also have a tendency to be high. The spatial patterns of the blue and green water flows are mainly influenced by the spatial patterns of precipitation. In addition, land cover contributes to the shaping of spatial patterns.

Green water flow calculations (maps not shown) indicated a slight decrease in evapotranspiration due to the assumption that land cover would not significantly change from the period of 1980 to 2010 in the future.

E. Climate change scenarios: The impacts of climate change on deep aquifer recharge

Figure 8 captures the anomaly maps of deep aquifer recharge (maps of percent deviation from historic data, 1980-2010) for A2, A1B and B1 scenarios for the periods 2046-2064 and 2080-2100 for the average change of multi-GCM ensemble. All scenarios in the near future (except under A2 scenario) and distant future indicated that the whole basin will experience increases in deep aquifer recharge. B1 projected the greatest increase in the near future $(100 \%)$. This trend increases further up to $150 \%$ in the distant future. A1B projected increases could be up to $40 \%$ for the near and distant future. A2 scenario projected decreases up to $7 \%$ in the mid-century and increases up to $10 \%$ at the end of the century. However, recharge might be overestimated because of the assumption of constancy of land cover in the model. 


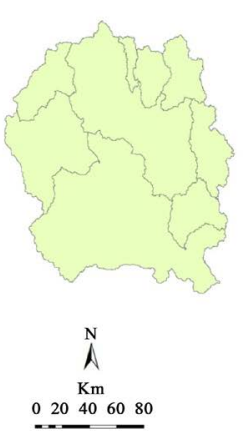

(a)

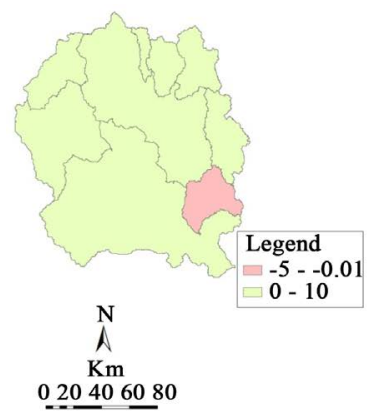

(d)
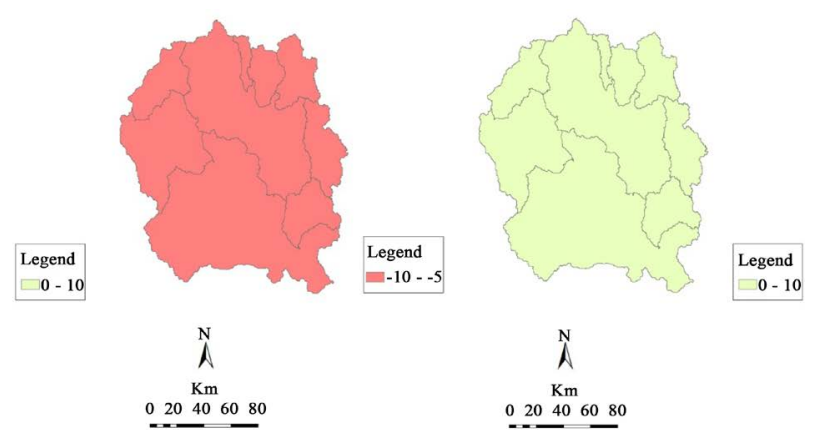

(b)

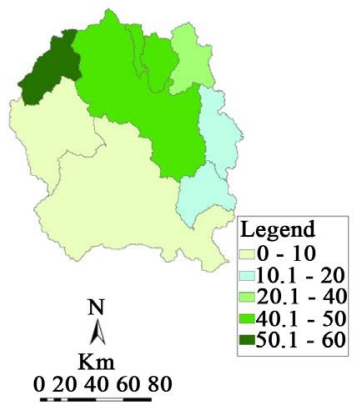

(e)

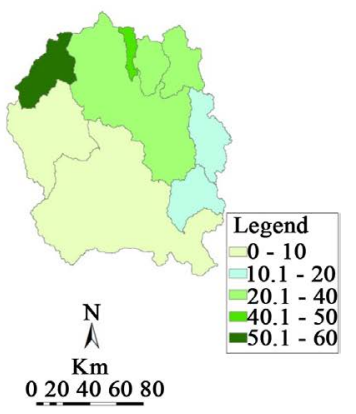

(f)

Figure 7. The impacts of climate change on the green water storage of the basin in ${ }^{\circ} \mathrm{C}$ (a) anomaly based on scenario $\mathrm{A} 2$ for the period of 2080-2100; (b) anomaly for A2 for 2046-2064; (c) anomaly for A1B for 2080-2100; (d) anomaly for A1B for 2046-2064; (e) anomaly for B1 for 2080-2100; and (f) anomaly for B1 for 2046-2064.

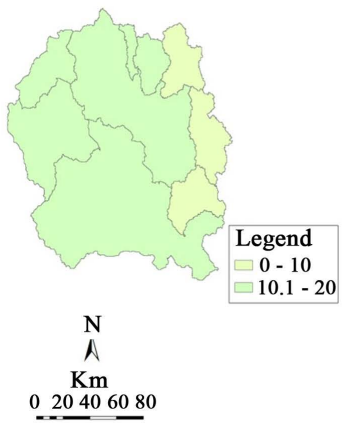

(a)

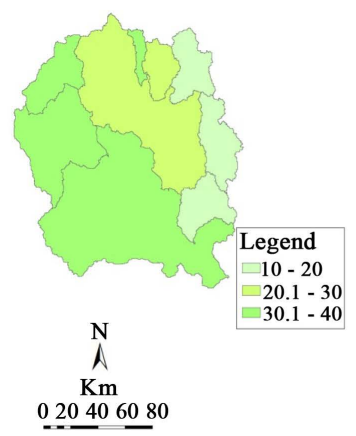

(d)
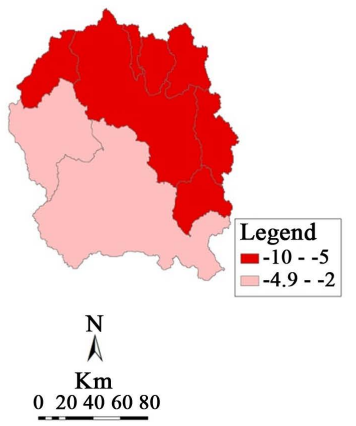

(b)

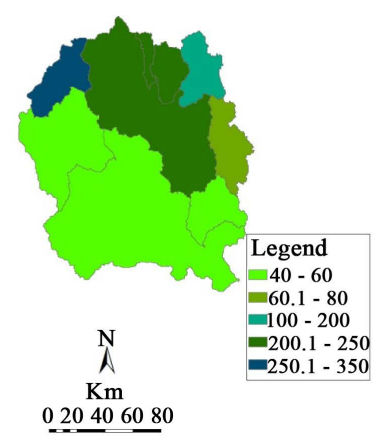

(e)

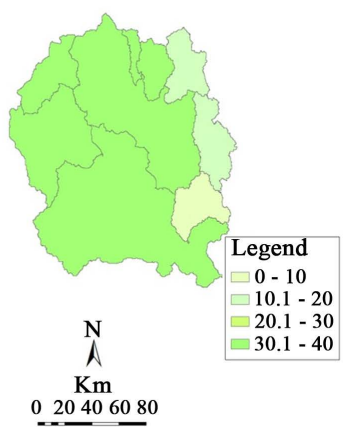

(c)

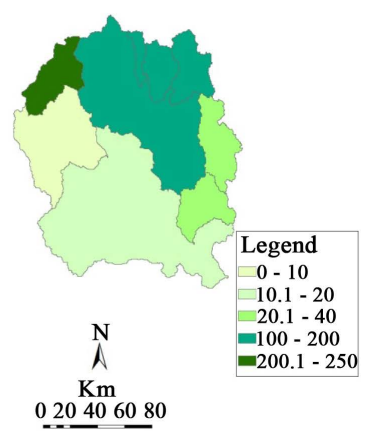

(f)

Figure 8. The impacts of climate change on the deep aquifer recharge of the basin in ${ }^{\circ} \mathrm{C}$ (a) anomaly based on scenario A2 for the period of 2080-2100; (b) anomaly for A2 for 2046-2064; (c) anomaly for A1B for 2080-2100; (d) anomaly for A1B for 2046-2064; (e) anomaly for B1 for 2080-2100; and (f) anomaly for B1 for 2046-2064. 
The results from the SWAT model clearly demonstrate that the water regime of the Isaac basin will experience a shift due to climate change, and most likely, for more water resources.

\section{Conclusions}

The Isaac River catchment in Central Queensland, Australia does not appear to be typical of other catchments of the world where the likely scenario due to climate change is aggravation of water scarcity rather than amelioration. While this could be beneficial for agriculture, the flipside of it is that there could be more severe floods or heavy downpours that could disrupt the economic activities of the region.

The ramifications, however, could be quite far-reaching. Owing to the proximity of the region to the Great Barrier Reef, the increased temperature is likely to increase coral bleach, and increased flow in rivers laden with sediments may introduce nutrients which could harm the marine environment.

\section{References}

[1] Parry, M.L., et al., Eds. (2007) Climate Change 2007: Impacts, Adaptation and Vulnerability, Contribution of Working Group II to the Fourth Assessment Report of IPCC, Cambridge University Press, Cambridge.

[2] Keenan, T. and Cleugh, H. (2011) Climate Science Update: A Report to the 2011 Garnaut Review. Centre for Australian Weather and Climate Research, Canberra.

[3] Issa, I.E., Al-Ansari, N., Sherwany, G. and Knutsson, S. (2014) Expected Future of Water Resources within TigrisEuphrates rivers Basin, Iraq. Journal of Water Resource and Protection, 6, 421-432. http://dx.doi.org/10.4236/jwarp.2014.65042

[4] Queensland Government (2016) Managing Fitzroy River Water Quality. https://www.fitzroyriver.qld.gov.au/

[5] Amos., K.J., Croke, J. C., Hughes, A. O., Chapman, J., Takken, I. and Lymburner, L. (2008) A Catchment-Scale Assessment of Anabranching in the $143000 \mathrm{~km}^{2}$ Fitzroy River Catchment, North-Eastern Australia. Earth Surface Processes and Landforms, 33, 1222-1241. http://dx.doi.org/10.1002/esp.1609

[6] Lough, J.M. (2007) Tropical River Flow and Rainfall Reconstructions from Coral Luminescence: Great Barrier Reef, Australia. Paleoceanography, 22, 1-16. http://onlinelibrary.wiley.com/doi/10.1029/2006PA001377/pdf

[7] Dougall, C. and Shaw, M. (2014) Modelling Reductions of Pollutant Loads Due to Improved Management Practices in the Great Barrier Reef Catchments. Technical Report, Department of Natural Resource and Mines, Rockhampton, Volume 4.

https://www.researchgate.net/publication/267338057_Modelling_reductions_of_pollutant_loads_due_to_improved_ma nagement_practices_in_the_Great_Barrier_Reef_catchments_-_Burdekin_NRM_region_Technical_Report_Volume_4

[8] Lucas, R., Crerar, J., Hardie, R., Merritt, J. and Kirsch, B. (2009) Isaac River Cumulative Impact Assessment of Mining Developments. Mining Technology, 118, 142-151. http://dx.doi.org/10.1179/174328610X12682159814902

[9] Arnold, J., Srinivasan, R. and Yang, J. (1998) Large Area Hydrologic Modeling and Assessment Part I: Model Development1. Journal of the American Water Resources Association, 34, 73-89. http://dx.doi.org/10.1111/j.1752-1688.1998.tb05961.x

[10] Green, W.H. and Ampt, G. (1911) Studies on Soil Physics, 1. The Flow of Air and Water through Soils. Journal of Agriculture Science, 4, 1-24.

[11] Food and Agriculture Organization (1995) The Digital Soil Map of the World and Derived Soil Properties. Version 3.5, Rome.

[12] Abbaspour, K., Yang, J., Maximov, I., Siber, R., Bogner, K., Mieleitner, J., Zobrist, J. and Srinivasan, R. (2007) Modelling Hydrology and Water Quality in the Pre-Alpine/Alpine Thur Watershed Using SWAT. Journal of Hydrology, 333, 413-430. http://dx.doi.org/10.1016/j.jhydrol.2006.09.014

[13] Nash, J. and Sutcliffe, J.V. (1970) River Flow Forecasting through Conceptual Models Part I-A Discussion of Principles. Journal of Hydrology, 10, 282-290. http://dx.doi.org/10.1016/0022-1694(70)90255-6

[14] Maurer, E.P., Brekke, L., Pruitt, T., Thrasher, B., Long, J., Duffy, P., Dettinger, M., Cayan, D. and Arnold, J. (2014) An Enhanced Archive Facilitating Climate Impacts and Adaptation Analysis. Bulletin of the American Meteorological Society, 95, 1011-1019. http://dx.doi.org/10.1175/BAMS-D-13-00126.1

[15] Cibin, R., Sudheer, K.P. and Chaubey, I. (2010) Sensitivity and Identifiability of Stream Flow Generation Parameters of the SWAT Model. Hydrological Processes, 24, 1133-1148. http://dx.doi.org/10.1002/hyp.7568

[16] Li, Z., Xu, Z., Shao, Q. and Yang, J. (2009) Parameter Estimation and Uncertainty Analysis of SWAT Model in Upper Reaches of the Heihe River Basin. Hydrological Processes, 23, 2744-2753. http://dx.doi.org/10.1002/hyp.7371 
[17] Chambers, L.E., Hughes, L. and Hughes, C. (2005) Climate Change and Its Impact on Australia’s Avifauna. Journal of Bird Life Australia, 105, 1-20.

[18] Head, L., Adams, M., McGregor, H.V. and Toole, S. (2014) Climate Change and Australia. Wiley Interdisciplinary Reviews: WIREs Climate Change, 5, 175-197. http://dx.doi.org/10.1002/wcc.255

Submit or recommend next manuscript to SCIRP and we will provide best service for you:

Accepting pre-submission inquiries through Email, Facebook, LinkedIn, Twitter, etc.

A wide selection of journals (inclusive of 9 subjects, more than 200 journals)

Providing 24-hour high-quality service

User-friendly online submission system

Fair and swift peer-review system

Efficient typesetting and proofreading procedure

Display of the result of downloads and visits, as well as the number of cited articles

Maximum dissemination of your research work

Submit your manuscript at: http://papersubmission.scirp.org/ 